\title{
POTENSI PEMBANGKIT PV-BATERAI SEBAGAI SUMBER LISTRIK DAERAH RURAL
}

\author{
OLNES Y. HUTAJULU \\ Tanri Abeng University \\ olnes.hutajulu@tau.ac.id
}

\begin{abstract}
Abstrak
Pakkat Pulo adalah sebuah Desa di Kabupaten Humbang Hasundutan, Sumatera Utara yang sebagian besar penduduknya belum mendapat suplai listrik. Jarak, tingkat kepadatan penduduk yang kecil, dan kurangnya produksi listrik menjadi penyebab permasalahan tersebut. Penelitian ini mengusulkan pembangkit photovoltaik-baterai $(P B)$ sebagai solusi kelistrikan tersebut. Studi teknis dan ekonomis dilakukan terhadap pembangkit PB di sampaikan pada artikel ini. Hasil penelitian menunjukkan, bahwa komposisi sistem yang direkomendasikan terdiri dari $750 \mathrm{wp}$ modul photovoltaik, 4.6kWh baterai dengan 2 kali penggantian, 500 watt inverter dengan 3 kali penggantian untuk mencukupi kebutuhan listrik desa Pakkat Pulo. Biaya produksi energi dari sistem tersebut diketahui sangat ekonomis yaitu $R p$ 1,182,07 /kWh dengan memanfaatkan bantuan modal dari Pemerintah tanpa adanya bunga pinjaman.
\end{abstract}

\section{Abstract}

Pakkat Pulo is a village in Humbang Hasundutan, North Sumatera which is still yet to receive electrical energy service of utility company. Distance, small population density, and low generating capacity are the main causes of this problem. This study propose the use of photovoltaic-battery (PB) power generation as the solution that can be applied to resolve this issue. Both technical and economic study of $P B$ power generation are presented in this paper. Recommended systems as a result from this study consists of 750 watt peak solar photovoltaic modules, $4.6 \mathrm{kWh}$ with 2 times replacement battery, 500 watt with 3 times replacement inverter to meet the needs of the electrification for one household consumer in Pakkat Pulo village. The cost of energy of $P B$ power is $1,182.07 \mathrm{IDR} / \mathrm{kWh}$ by relying on Goverment loans without loan interest.

Keywords : economy studi, technical study, cost of energy, photovoltaic, baterai, household electricity. 


\section{PENDAHULUAN}

Indonesia merupakan Negara kepulauan dengan tiap pulau dipisahkan oleh laut. Beberapa daerah dapat menghasilkan energi listrik yang melebihi kebutuhan, namun ada daerah lain kekurangan. Distribusi energi listrik dari daerah yang kelebihan ke daerah kekurangan menjadi sangat sulit. Akibatnya, suplai energi listrik menjadi tidak merata yang ditandai dengan adanya daerah yang tidak mendapat pasokan energi listrik.

Solusi-solusi yang tercepat untuk ditawarkan guna memenuhi kebutuhan energi listrik di daerah terpencil adalah penggunaan generator set (genset) berbahan bakar solar maupun pemanfaatan energi terbarukan seperti, pembangkit mikrohidro, turbin angin, photovoltaic (PV) dan sebagainya. Namun semua pembangkit tersebut tidak dapat diaplikasikan di setiap daerah, sehingga perlu adanya pemilihan pembangkit yang tepat sesuai dengan potensi daerah yang menjadi objek pemasangan pembangkit. Generator diesel misalnya, membutuhkan biaya operasional yang besar akibat harga bahan bakar yang mahal dan jarak tempuh yang jauh. Pembangkit energi terbarukan seperti mikrohidro, turbin angin dan sebagainya juga membutuhkan sumber daya alam seperti sungai dan kecepatan angin sebagai bahan bakarnya. Ketidaktersediaan sumber daya inilah yang menjadi perhatian peneliti untuk melakukan penelitian yang menghasilkan sistem pembangkit yang sesuai untuk semua daerah yaitu pembangkit sistem hibrid.

\section{STUDI TEKNIS}

Lokasi penelitian adalah sebuah desa di Kabupaten Humbang Hasundutan (Humbahas) yaitu desa Pulo Pakkat yang terdiri dari 160 Kepala Keluarga (KK). Secara geografis, lokasi penelitian berada pada $2^{0}$ 9.2' $\mathrm{LU}$ dan $98^{0}$ 
28.4' BT. Kebutuhan energi listrik rata-rata untuk setiap pelanggan rumah tangga golongan R1 berdasarkan statistik data Perusahaan Listrik Negara (PLN) adalah $4 \mathrm{kWh} / \mathrm{hari}$.

Potensi matahari yang terdapat pada desa ini dapat diketahui dengan menggunakan sebuah perangkat lunak dari National Renewable Energi Laboratory (NREL) yang dikenal dengan Hybrid Optimization of Multiple Energi Resources (HOMER) versi percobaan (trial). Fitur cari lokasi dan sumber daya (sources) dapat dimanfaatkan untuk mengetahui potensi alam sebuah daerah, dimana salah satunya adalah potesi matahari. Data yang dihasilkan HOMER terintegrasi dengan situs online National Aeronautics and Space Administration (NASA), sehingga dapat dijamin keakuratannya. Adapun besarnya potensi energi matahari yang dapat diubah menjadi energi listrik diperlihatkan pada Tabel 1 dengan potensi rata-rata mencapai $4.63 \mathrm{kWh} / \mathrm{m}^{2} /$ day.

\subsection{Kapasitas dan Luas Lahan untuk Photovoltaik Array}

Pembangkit hibrid menggunakan PV umumnya dipasang dalam bentuk array, sehingga memerlukan ruang/area sebagai tempat pemasangan. Luas area yang dibutuhkan dapat diketahui dengan menggunakan Persamaan 1 yang sebelumnya digunakan oleh Giriantari, dkk.

$$
P V_{\text {area }}=\frac{E_{L}}{G_{A V} \cdot \eta_{p v} \cdot T C F}
$$

$\mathrm{E}_{\mathrm{L}}$ adalah rata-rata penggunaan energi listrik oleh pelanggan rumah tangga (pada penelitian ini) yaitu $4 \mathrm{kWh} / \mathrm{hari}, \mathrm{G}_{\mathrm{AV}}$ merupakan potensi energi listrik rata-rata yang dapat dihasilkan oleh cahaya matahari di lokasi sebesar 4.63 $\mathrm{kWh} / \mathrm{m} 2 /$ hari, TCF merupakan temperature correction factor sebesar 0,97 
dan $\boldsymbol{\eta}_{\mathrm{pv}}$ adalah efisiensi modul PV yang digunakan yaitu $0,16 \%$ dengan jenis polycristalline.

Luas area PV pada Persamaan 1 dapat digunakan untuk menhitung kapasitas daya PV dan jumlah modulnya dengan merujuk pada Persamaan 2 dan Persamaan 3.

\begin{tabular}{lcc}
\hline \multicolumn{1}{c}{ Bulan } & $\begin{array}{c}\text { Indeks } \\
\text { Kecerahan }\end{array}$ & $\begin{array}{c}\text { Radiasi harian } \\
(\mathbf{k W h} / \mathbf{m} 2 / \mathbf{h a r i})\end{array}$ \\
\hline Januari & 0.479 & 4.710 \\
Pebruari & 0.497 & 5.090 \\
Maret & 0.471 & 4.930 \\
April & 0.463 & 4.760 \\
Mei & 0.487 & 4.790 \\
Juni & 0.500 & 4.770 \\
Juli & 0.478 & 4.610 \\
Agustus & 0.450 & 4.530 \\
September & 0.427 & 4.420 \\
Oktober & 0.426 & 4.360 \\
November & 0.422 & 4.160 \\
Desember & 0.453 & 4.370 \\
\hline \multicolumn{2}{c}{ Radiasi rata-rata $\left(\mathbf{R}_{\text {av }}\right)$} & $\mathbf{4 . 6 3 0}$ \\
\hline
\end{tabular}

Sumber : NASA Surface meteorology and Solar Energy (2016). https:/leosweb.larc.nasa.gov/ssel

$$
W_{p v}=P V_{\text {area }} \cdot S T C \cdot \eta_{p v}
$$

$$
N_{p v}=\frac{W_{p v}}{P_{p v}}
$$

$\mathrm{W}_{\mathrm{P}}$ merupakan daya total PV yang diperlukan dan STC merupakan standart test condition sebesar $1000 \mathrm{kWh} / \mathrm{m}^{2}$ dan $\mathrm{P}_{\mathrm{pv}}$ merupakan daya tiap modul PV yang digunakan. 


\subsection{Menghitung Kapasitas Baterai}

Baterai merupakan bagian sistem yang vital, mengingat seluruh energi listrik dari PV di simpan ke baterai. Baterai dalam proses kerjanya memiliki batasan yang harus diperhatikan yaitu depth of charge (DOC) atau batas pemakaian. Tujuan dari pembatasan ini untuk mengoptimalkan masa pakai baterai. Persentase DOC baterai yang baik menurut standar IEEE 1013-2007 adalah $80 \%$. Jumlah baterai yang diperlukan sistem pada dasarnya dapat diketahui menggunakan Persamaan 4.

$$
N_{b a t}=\frac{E_{L}}{E_{b a t}}
$$

Akibat adanya pembatasan pemakaian energi dari baterai, maka diperlukan modifikasi persamaan seperti yang terlihat pada Persamaan 5 dengan $\mathrm{E}_{\text {bat }}$ adalah energi maksimal dari satu unit baterai

$$
N_{b a t}=\frac{E_{L}}{E_{b a t}+\left(E_{b a t}-\left(D O D \cdot E_{b a t}\right)\right.}
$$

\subsection{Inverter dan Perlengkapan lainnya}

Listrik yang dihasilkan oleh PV-Baterai berbentuk direct current (DC), sedangkan Listrik yang diperlukan oleh peralatan rumah tangga agar dapat beroperasi berbentuk alternating current (AC). Agar dapat menyesuaikan bentuk energi listrik yang dihasilkan pembangkit dan peralatan, maka diperlukan inverter. Inverter yang tersedia terdiri dari 2 jenis yaitu, inverter pure sine dan inverter modified pure sine. Jenis inverter yang digunakan pada penelitian ini adalah jenis pure sine karena menghasilkan listrik AC dengan bentuk sinyal yang stabil dan kapasitasnya sama dengan spesifikasi yang tertulis pada name plate alat. 


\subsection{Desain Pembangkit PV-Baterai}

Desain pembangkit hybrid PV-baterai yang diusulkan pada paper ini diperlihatkan pada Gambar 1. Pembangkit PV-Baterai terdiri dari modul PV, baterai dan inverter dengan kapasitas masing-masing diperoleh dari Persamaan 3 dan 5.

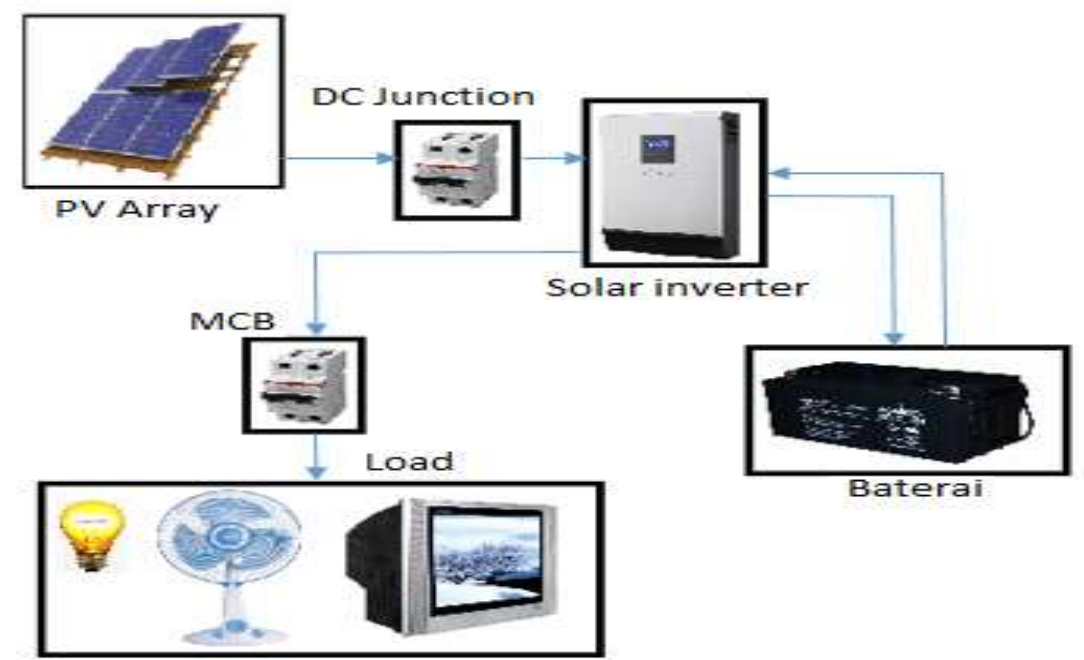

Gambar 1. Desain pembangkit hibrid PV-baterai.

Sebagai penduduk daerah tertinggal yang akan mempergunakan pembangkit listrik alternatif, maka besar beban yang digunakan sebagai bahan perhitungan disesuaikan dengan golongan R1. Berdasarkan data Perusahaan Listrik Negara (PLN), rata-rata pemakaian energi pelanggan R1 tiap bulannya adalah $4 \mathrm{kWh} / \mathrm{hari}$. Data ini kemudian dipergunakan untuk menghitung kapasitas dari tiap-tiap komponen pembangkit PV-Baterai sesuai dengan Persamaan 3 dan 5.

Berdasarkan persamaan 3 dan 5, jumlah dan kapasitas masing-masing perlengkapan untuk membangun pembangkit hibrid PV-baterai sebagai sarana elektrifikasi pelanggan rumah R1 di desa Pulo Pakkat seperti dapat di 
lihat pada Tabel 2. Harga alat dan bahan pada Tabel 2 dapat dilihat pada halaman website distributor yang beroperasi di Indonesia.

Besarnya energi listrik rata-rata yang dihasilkan modul PV $\left(\mathrm{E}_{\mathrm{pv}}\right)$ setiap hari dapat diketahui dengan menggunakan Persamaan 6.

$$
E_{p v}=\frac{N_{p v}}{S T C} \cdot R_{a v} \cdot \mathrm{Q}
$$

Table 2. Perlengkapan sistem PV-baterai [10].

\begin{tabular}{|c|c|c|}
\hline Alat & Spesifikasi dan Harga & Penggantian \\
\hline PV & $\begin{array}{l}\text { a. Ppv = 250wp } \\
\text { b. } \mathrm{Np}=4 \\
\text { c. Harga/unit = Rp } \\
\text { 4,350,000.00 } \\
\text { d. Masa pakai = 25 tahun }\end{array}$ & Tidak ada \\
\hline Baterai & $\begin{array}{l}\text { a. Ebat }=1,200 \mathrm{Wh} \\
\text { b. Nbat }=4 \\
\text { c. Harga/unit = Rp } \\
\text { 2,300,000.00 } \\
\text { d. Masa Pakai = } 15 \text { tahun }\end{array}$ & 1 kali \\
\hline Inverter & $\begin{array}{l}\text { a. Daya = 500 watt } \\
\text { b. Jumlah = } 1 \\
\text { c. Harga = Rp 1,750,000.00 } \\
\text { d. Masa pakai = } 10 \text { tahun }\end{array}$ & 2 kali \\
\hline Solar charger & $\begin{array}{l}\text { a. Tegangan=12 V } \\
\text { b. Arus }=10 \mathrm{~A} \\
\text { c. Jumlah = } 1 \\
\text { d. Harga = Rp 400,000.00 } \\
\text { e. Masa pakai = 25 tahun }\end{array}$ & Tidak ada \\
\hline Kontaktor & $\begin{array}{l}\text { a. Jumlah }=2 \\
\text { b. Harga }=\text { Rp 100,000.00 }\end{array}$ & 1 kali \\
\hline $\begin{array}{l}\text { Perlengkapan } \\
\text { lain }\end{array}$ & $\begin{array}{l}\text { a. } \text { Jumlah }=1 \text { set } \\
\text { b. Harga }=\text { Rp } 300,000.00\end{array}$ & 1 kali \\
\hline
\end{tabular}

Pada Persamaan 6, Q merupakan quality factor seperti yang digunakan Schmid pada penelitiannya. Perbedaan Persamaan 6 dengan Persamaan 2 adalah Persamaan 6 merupakan energi real yang dihasilkan modul PV sedangkan Persamaan 2 adalah energi listrik ideal yang diharapkan dihasilkan modul PV. 


\section{STUDY BIAYA}

\subsection{Desain Pembangkit PV-Baterai}

Pembangkit hibrid menggunakan PV akan memperoleh nilai ekonomis jika sistem beroperasi minimal 10 tahun . Oleh sebab itu, pada penelitian ini, analisis biaya dilakukan untuk pembangkit dengan masa operasional 25 tahun. Biaya total sistem atau total cost $\left(\mathrm{C}_{\text {tot }}\right)$ merupakan penjumlahan dari seluruh biaya yang dikeluarkan untuk operasional sistem yang terdiri dari biaya awal (pemasangan) atau initial cost $\left(\mathrm{C}_{\text {in }}\right)$, biaya perawatan atau maintenance cost $\left(\mathrm{C}_{\mathrm{m}}\right)$ dan biaya penggantian alat atau replacement cost $\left(\mathrm{C}_{\text {rep }}\right)$ dari tiap-tiap komponen pembangkit selama 25 tahun. Biaya total diperoleh menggunakan Persamaan 7.

$$
C_{t o t}=C i_{p v}+C i_{b a t}+C i_{i n v}
$$

$\mathrm{Ci}_{\mathrm{pv}}, \mathrm{Ci}_{\text {bat }}$ dan $\mathrm{Ci}_{\mathrm{inv}}$ masing-masing adalah biaya total yang dikeluarkan untuk PV, baterai dan inverter selama 25 tahun sistem beroperasi. $C_{i}$ terdiri dari biaya awal, biaya perawatan dan biaya penggantian komponen. Sistem pemodalan yang diusulkan terdiri dari 2 skenario yaitu:

a. Skenario 1: Modal pembangunan pembangkit dengan pinjaman tanpa bunga (pemodalan dari pemerintah), dan

b. Skenario 2: Menggunakan pinjaman dari bank.

Suku bunga (interest rate) yang digunakan mengacu pada kebijakan Bank Indonesia (BI) sebesar 6,5\% per tahun. Kalkulasi biaya total dari pembangkit PV-Baterai untuk penelitian ini dihitung berdasarkan Persamaan 8.

$$
C_{t o t}=C_{t o t}+\left(\left(C_{t o t} . i\right) * 25\right)
$$




\subsection{Desain Pembangkit PV-Baterai}

Biaya produksi energi atau cost of energy (COE) merupakan harga untuk tiap $1 \mathrm{kWh}$ energi yang dihasilkan oleh pembangkit selama masa operasi pembangkit (25 tahun). Berdasarkan nilai $\mathrm{COE}$, perusahaan listrik dapat menentukan harga jual listrik ke pelanggan. COE dapat diketahui dengan menggunakan Persamaan 9.

$$
C O E=\frac{C_{t o t}}{E_{\text {tot }}}
$$

$\mathrm{E}_{\text {tot }}$ merupakan energi yang dihasilkan oleh pembangkit selama kurun waktu tertentu (misalnya 1 tahun). $\mathrm{E}_{\text {tot }}$ yang dihitung pada penelitian ini adalah total energi selama 25 tahun seperti terlihat pada Persamaan 10.

$$
E_{\text {tot }}=\sum_{n=25}^{365} E_{p v-b a t}
$$

$\mathrm{E}_{\mathrm{pv} \text {-bat }}$ adalah energi yang dihasilkan oleh pembangkit PV-baterai per hari.

\section{HASIL DAN PEMBAHASAN}

\subsection{Hasil}

Penelitian menggunakan nilai cost of energy (COE) sebagai acuan dalam menentukan tingkat ekonomi dari pembangkit hibrid PV-baterai yang diteliti. Berdasarkan persamaan-persamaan yang telah diberikan, maka diperoleh hasil perhitungan teknis dan analisis biaya yang perlihatkan pada Tabel 3. 
Table 3. Hasil analisis teknis dan biaya.

\begin{tabular}{|c|c|c|c|}
\hline $\begin{array}{c}\text { Jenis } \\
\text { Analisis }\end{array}$ & Besaran & Satuan & Nilai \\
\hline \multirow{5}{*}{ Teknis } & $\mathrm{R}_{\mathrm{av}}$ & $\mathrm{m}^{2}$ & 5.57 \\
\hline & $\mathrm{W}_{\mathrm{pv}}$ & wp & 892.00 \\
\hline & $\mathrm{E}_{\mathrm{PV}}$ & $\mathrm{kWh}$ & 3.94 \\
\hline & $\mathrm{N}_{\text {bat }}$ & unit & 4.00 \\
\hline & $\mathrm{E}_{\text {tot }}$ & $\mathrm{kWh}$ & $35,911.43$ \\
\hline \multirow{4}{*}{ Biaya } & $\mathrm{C}_{\text {tot }}$ skenario 1 & $\mathrm{Rp}$ & $42,450,000.00$ \\
\hline & $\mathrm{C}_{\text {tot }}$ skenario 2 & $\mathrm{Rp}$ & $111,431,250.00$ \\
\hline & COE skenario 1 & $\mathbf{R p}$ & $1,182.07$ \\
\hline & COE skenario 2 & $\mathbf{R p}$ & $3,102.95$ \\
\hline
\end{tabular}

\subsection{Pembahasan}

Merujuk kepada hasil penelitian yang ditampilkan pada Tabel 3, diketahui bahwa peluang pemanfaatan pembangkit PV-Baterai dengan skenario $1 \mathrm{Rp}$. 1,182.07 per $\mathrm{kWh}$. Nilai tersebut lebih kecil dibandingkan COE dari generator diesel yang mencapai lebih dari Rp 3,000.00. Namun berbeda dengan generator diesel set (genset) yang memiliki biaya investasi yang murah, pembangkit sistem PV-Baterai memerlukan biaya investasi yang sangat besar. Realisasi dari sistem ini hanya dapat dilakukan jika pemerintah bersedia memberi bantuan modal tanpa bunga kepada masyarakat.

\section{KESIMPULAN}

Pembangkit listrik sistem PV-Baterai merupakan sistem pembangkit yang menjanjikan sebagai solusi elektrifikasi daerah remote/rural. Peluang ini perlu dimanfaatkan oleh pemerintah untuk menjawab tuntutan elektrifikasi $100 \%$ di Indonesia sehingga setiap daerah memperoleh fasilitas yang sama yaitu mendapat suplai energi listrik. Penggunaan generator diesel merupakan solusi yang cepat, namun konsekuensinya adalah, perlunya biaya operasi 
harian yang tinggi. Mengingat kapasitas bahan bakar fosil yang semain tinggi dan berdapmpak kepada harga jualnya, generator diesel ke depannya tidak dapat lagi digunakan sebagai solusi. Oleh sebab itu, pembangkit PV-Baterai dapat menggantikannya dengan harganya yang ekonomis serta ramah lingkungan menjadi nilai tambahnya.

\section{DAFTAR PUSTAKA}

Altestore. Pure Sine Wave Vs Modified Sine Wave Inverter - What's the Difference?. Diakses di https://www.altestore.com/blog/2015/10/puresine-wave-vs-modified-sine-wave-whats-the-difference/, 1 November 2017.

Bajpai, P., \& Dash, V. 2012. Hybrid renewable energy systems for power generation in stand-alone applications: A review, Renewable and Sustainable Energy Reviews, pp. 2926-2939.

Bank Indonesia,. BI Rate. Diakses di. http://www.bi.go.id/id/moneter/birate/data/Default.aspx, 1 November 2017.

Chowdhury, S. A., \& Mourshed, M. 2016. Off-grid electrification with solar home systems: An appraisal of the quality of components. Renewable Energy, pp. 585-598.

Dirjen Kementrian ESDM. Statistik Kelistrikan 2015. Diakses di https://djk.esdm.go.id/pdf/Buku\%20Statistik\%20Ketenagalistrikan/Stat istik\%20Ketenagalistrikan\%20T.A.\%202016.pdf. 1 November 2015.

Giriantari, I. A. D. 2014. Economic Cost Study of Photovoltaic Solar System for Hotel in Nusa Lembongan. ICSGTEIS, pp. 5-7.

Halder, P. K. 2016. Potential and economic feasibility of solar home systems implementation in Bangladesh. Renewable and Sustainable Energy Reviews, pp. 568-576.

PanelSurya Jakarta,. Panel Surya. Diakses di http://panelsuryajakarta.com/category/panel-surya/, 1 November 2017. 
Schmid, J. 2007. Real Energy Production of Residential Photovoltaic Systems. Domestic use of Electrical Energy Conference. pp. 134-137.

Standards, I., Committee, C., Generation, D., \& Storage, E. 2007. IEEE Recommended Practice for Sizing Lead-Acid Batteries for Stand-Alone Photovoltaic $(P V)$ Systems. IEEE Standards Coordinating Committee 21. 20 July.

TGJ LIPI. Pengembangan Energi Terbarukan Sebagai Energi Adiftif di Indonesia, LIPI, Diakses di http://www.energi.lipi.go.id/utama.cgi?artikel\&1101089425\&9, $\quad 01$ Januari 2017.

Y. Gurkaynak, Z. Li, and A. Khaligh. 2009. A novel grid-tied, solar powered residential home with plug-in hybrid electric vehicle (PHEV) loads, IEEE Vehicle Power Propuls. Conf., Dearborn, pp. 813-816.

Zahedi, A. 2006. Solar photovoltaic ( PV) energy; latest developments in the building integrated and hybrid PV systems. Renewable Energy. pp. 711-718. 